\title{
Systematic approach toward the clinical diagnosis of functional dyspepsia
}

\author{
Pierre Paré MD FRCPC FACG
}

\begin{abstract}
P Paré. Systematic approach toward the clinical diagnosis of functional dyspepsia. Can J Gastroenterol 1999;13(8):647-654. Functional dyspepsia (FD) is the most common condition in patients consulting with upper gastrointestinal tract symptoms, resulting in up to $5 \%$ of visits to family physicians. By definition, patients with FD have no clinical, biochemical or endoscopic evidence of an organic disease that is likely to explain their symptoms. The process to be used in a structured interview for establishing a clinical diagnosis of FD is presented. The steps are as follows: determine the duration and the course of the disease; characterize the current syndrome and review the alarm symptoms; elicit the patient-perceived dominant symptom and/or condition; and identify the patient's reason for consulting and address the psychosocial factors. According to the clinical characteristics of the three most frequent causes of dyspepsia (peptic ulcer, gastroesophageal reflux and FD) and acknowledging that these conditions may coexist rather than overlap in some patients, an algorithm is suggested for establishing a working diagnosis of FD and indications for investigation, and initiating a management strategy.
\end{abstract}

Key Words: Functional dyspepsia; Structured interview

\section{Approche systématique pour le diagnostic clinique de la dyspepsie fonctionnelle}

\begin{abstract}
RÉSUMÉ : La dyspepsie fonctionnelle (DF) est la maladie la plus répandue chez les patients qui consultent pour des symptômes des voies digestives hautes et serait à la base de jusqu'à $5 \%$ des consultations auprès des médecins de famille. Par définition, les patients qui souffrent de DF n'ont aucun signe clinique, biochimique ou endoscopique de maladie organique qui puisse expliquer leurs symptômes. Nous présentons ici le processus à utiliser pour une entrevue structurée afin d'établir le diagnostic clinique de DF. Les étapes sont les suivantes : déterminer la durée et l'évolution de la maladie dans le temps, caractériser le syndrome actuel et revoir les symptômes cardinaux, demander au patient quel est le symptôme ou le problème qu'il perçoit comme dominant, identifier la raison pour laquelle le patient consulte et envisager les facteurs psychosociaux. Selon les caractéristiques cliniques des trois causes les plus fréquentes de dyspepsie (ulcère gastro-duodénal, œsophagite de reflux et DF) et reconnaissant que ces maladies peuvent coexister plutôt que de se chevaucher chez certains patients, un algorithme est suggéré pour l'établissement d'un diagnostic préliminaire de DF, les épreuves diagnostiques nécessaires et l'amorce d'une stratégie thérapeutique.
\end{abstract}

$\mathrm{D}$ yspepsia is a common symptom complex in the general population. In several countries (1-4) including Canada (5), it is estimated that approximately $25 \%$ of adults in the community report such complaints at some time. In population-based follow-up studies $(3,6,7)$, a fluctuating pattern is observed because the proportion of normal subjects developing symptoms is similar to the proportion of those going into remission, so that the overall prevalence rate is unchanged from year to year. Although only a minority of subjects report having seen a physician for their symptoms $(2,4,6,8,9)$, dyspepsia accounts for up to $5 \%$ of consultations in family practice (10). When patients are appropriately in- vestigated, less than half have an underlying structural explanation for their symptoms, such as peptic ulcer or macroscopic reflux esophagitis. The majority of the remaining group is classified as having functional (or nonulcer) dyspepsia (FD) (11-13), even though this group includes an undetermined proportion of patients with normal endoscopy gastroesophageal reflux disease (GERD). FD has important social and economic effects. Costs are mainly due to work absenteeism and physician visits - more commonly for nongastrointestinal symptoms than for gastrointestinal symptoms $(4,14,15)$. Interestingly, a Swedish study (15) found that investigation and treatment were responsible for only a

Division of Gastroenterology, Quebec City University Medical Centre, Pavillon L'Hotel-Dieu de Quebec, Laval University, Québec, Québec Correspondence and reprints: Dr Pierre Paré, Quebec City University Medical Centre, Pavillon L'Hotel-Dieu de Quebec, 11 Côte du Palais,

Québec, Québec G1R 2J6. Telephone 418-691-5252, fax 418-691-5348, e-mail parep@sympatico.ca

Received for publication September 17, 1998. Accepted January 26, 1999 
TABLE 1

Suggested clinical process to establish a working diagnosis in patients with uninvestigated dyspepsia

Objective: Establish a symptom-based diagnosis

Process: Structured interview

1. Determine the duration and the course of the disease

2. Characterize the current syndrome and review the alarm symptoms

3. Determine the patient-perceived dominant symptom and/or condition

4. Identify the patient's reason for consulting and address the psychosocial factors

Caution: Ascertain, when appropriate, that the upper gastrointestinal tract is normal

small proportion of the expenses associated with FD. Accordingly, the role of family physicians is very important for these patients.

Many definitions of dyspepsia have been proposed. The British Society of Gastroenterology, in 1996, defined dyspepsia as a group of symptoms that alerts doctors to consider disease of the upper gastrointestinal tract (16). This generic definition includes GERD, peptic ulcer disease (PUD) and FD as the most common conditions after exclusion, with appropriate investigations, of diseases that may mimick or present themselves as dyspepsia. Cardiac disease, abdominal wall pain and somatoform disorder are examples that may add confusion and make differential diagnosis difficult for the clinician.

A group of international clinical investigators proposed that FD be defined as a clinical syndrome of persistent or recurrent pain or discomfort centred in the upper abdomen occuring in patients with no clinical, biochemical, endoscopic or ultrasonographic evidence of known organic disease likely to explain the symptoms (1). FD has been further classified into ulcer-type and dysmotility-type (based on symptom clusters), and an unspecified type (symptoms not fitting into previous categories). Dominant gastroesophageal reflux symptoms belong to a distinct clinical entity (1). However, results from community-based studies of subjects with undiagnosed dyspepsia and studies of patients referred for dyspepsia do not support the clinical relevance or the predictive accuracy of these symptomatic subgroups $(2,17)$. Accurate clinical diagnosis would potentially result in the identification of specific and/or appropriate management strategies in patients with dyspepsia. The lack of clinical utility of subgrouping dyspepsia is also reflected by current guidelines that encourage testing for Helicobacter pylori as the initial step in the management of dyspeptic patients in the community $(18,19)$. Interestingly, in a recent survey of Canadian primary care physicians submitted to scenarios of uninvestigated patients with reflux-type, ulcer-type and dysmotilitytype dyspepsia, the majority found this subgroup classification useful for patient management (20). In clinical practice, the value of establishing a clinical working diagnosis remains unresolved.

Conclusions about the lack of clinical utility of symptomatic clusters in patients with undiagnosed dyspepsia and in patients with FD may diverge with the clinical impression because of the content of the questionnaires and/or the process leading to diagnosis used in those studies. The discriminative value and the precision of the questions used may not have been optimal. For instance, in the most commonly used questionnaire proposed by Talley et al $(21,22)$, patients' understanding of heartburn was not assessed; in this case, a prolonged retrosternal burning pain unrelieved by food or antacid could have been mistaken for heartburn. A cutoff level of $75 \%$ for the frequency of relief, not uncommonly observed in patients with PUD, would yield better discrimination between ulcer-type and dysmotility-type subgroups. Due to the high placebo effect in FD, one may predict relief $25 \%$ of the time or more in most patients. Symptoms frequently overlap between subgroups $(2,3,17)$ but there are no data supporting the hypothesis that similar upper gastrointestinal tract symptoms may be explained by different pathophysiological mechanisms. For example, epigastric bloating or discomfort and early satiety may not be due to gastric dysfunction in dysmotility-like dyspepsia, and explained by lower esophageal sphincter and esophageal dysfunctions in a patient with predominant heartburn and those same symptoms. Furthermore, including patients with primary or associated somatoform disorders may add to the confusion.

The following suggested systematic approach for the clinical diagnosis of FD at the primary care level is the result of the author's critical analysis of the previous and current literature and clinical experience. Participation of the author in a Canadian Non Ulcer Dyspepsia Working Group composed of 10 gastroenterologists and one family physician influenced this proposal. However, this is not a report of the conclusions achieved by this group.

\section{ESTABLISHING A CLINICAL DIAGNOSIS OF FD}

Table 1 suggests a process to establish a working clinical diagnosis of FD through a structured interview with patients consulting with undiagnosed dyspepsia. For patients at the primary care level, the objective is to initiate a symptombased diagnosis to differentiate among structural causes of dyspepsia, nongastrointestinal causes of symptoms and FD. This approach is reasonable because dyspepsia and FD are so common and because specific therapeutic measures and outcomes are available for PUD and GERD. Indeed, the recommendation of the American College of Physicians in 1985 (23) to first initiate a therapeutic trial in patients with undiagnosed dyspepsia and no alarm symptoms and signs conflicts with current knowledge. Eradication of $\mathrm{H}$ pylori cures almost all patients with PUD not taking nonsteroidal antiinflammatory drugs (24), GERD is a chronic condition often requiring long term or intermittent drug therapies (25), and there is a limited therapeutic role of acid inhibitory drugs but a high potential for a placebo effect in FD (26-28). Furthermore, the Canadian (24) and the American (29) Consensus on Helicobacter pylori, in contrast to the European Consensus (18) and the guidelines of the American Gastroenterological Association (19), do not recommend a routine first-time 


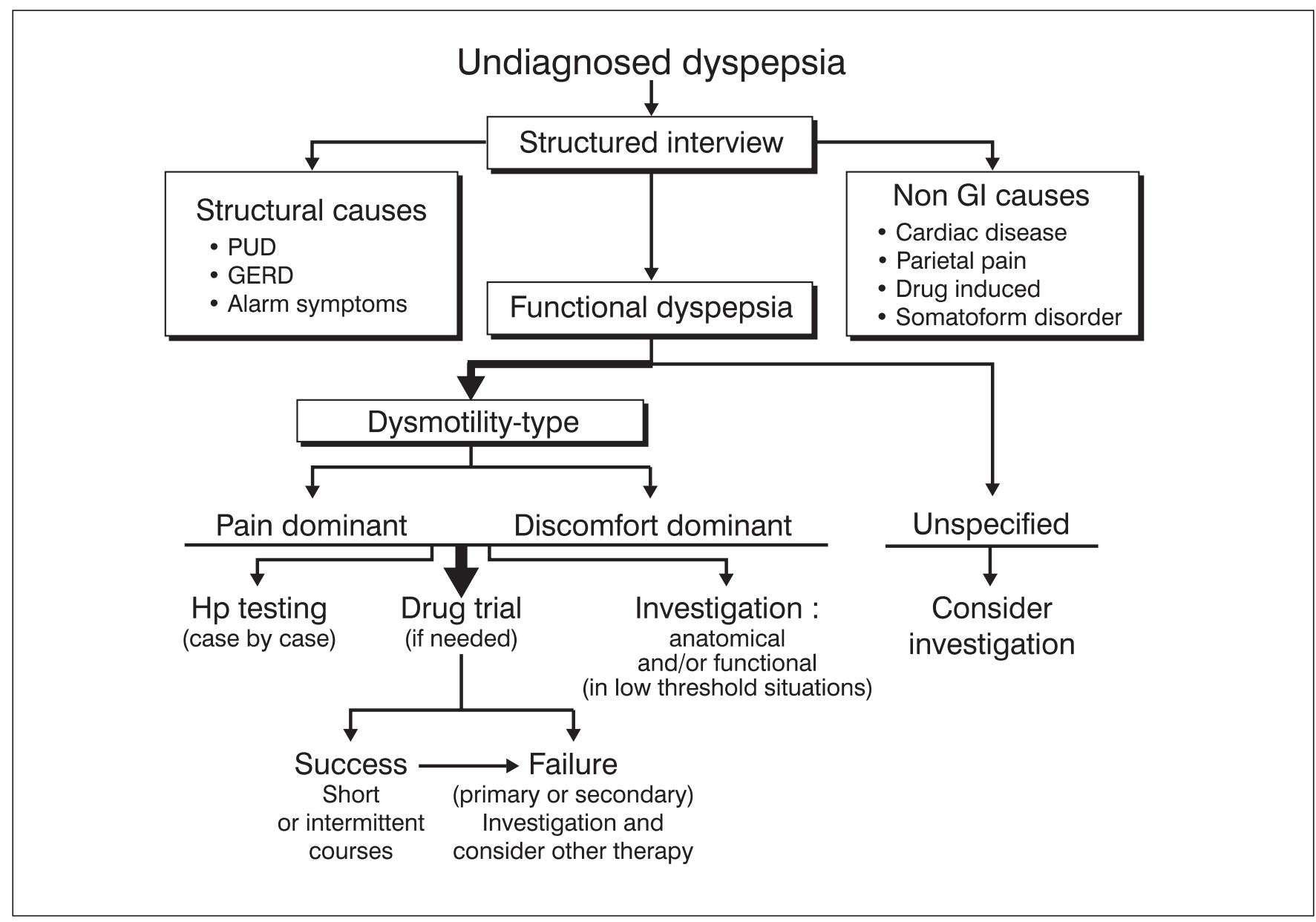

Figure 1) Suggested approach to the clinical diagnosis and management of functional dyspepsia. GERD Gastroesophageal reflux disease; GI Gastrointestinal; Hp Helicobacter pylori; PUD Peptic ulcer disease

strategy to test for $H$ pylori in all patients with uninvestigated dyspepsia or with presumed FD (except on a case by case basis), or in patients with GERD. Although the predictive value of developing a symptom-based diagnosis is still an issue to debate and the cost-benefit ratio of consequent management strategies has not yet been established from clinical trials, patient and physician satisfaction is likely to be enhanced with such a focused approach. This approach can be seen as a step forward in the process of determining a definite diagnosis, which would result, at least in part, in the same positive effects of initial endoscopy versus an initial therapeutic trial on patient satisfaction and on the use of health care resources (30).

Structured interview: Most patients consulting with dyspepsia tend to focus on selective symptoms and factors that are important to them. However, it is necessary to take a systematic history to conduct an accurate and complete differential diagnosis and to review items that help the physician perform a global assessment. This approach may allow physicians to initiate early a management strategy in patients with FD.

Step 1: Determine the duration and course of the disease: The three most common causes of dyspepsia have a chronic course. However, the patients often do not spontaneously report all details of their disease history that may reveal distinctive diagnostic features. PUD is a chronic relapsing disease unless $H$ pylori is eradicated or maintenance therapy is given (31). Therefore, these patients have a disease with often totally asymptomatic periods of weeks to years and some episodes of recurrent symptoms. Most untreated patients with GERD, with or without macroscopic esophagitis, also have chronic intermittent symptoms of varying frequency but with no periodicity $(32,33)$. Patients with FD also have a chronic nonperiodic but fluctuating condition. In a recent international therapeutic trial involving more than 1200 patients with FD, about two of three had a disease duration of more than one year (34). In two communitybased studies, symptoms of dyspepsia were still present in most patients two years later $(6,7)$. Not all patients with FD seek medical attention $(4,35)$. In two large epidemiological studies, the frequency of health care visits was $25 \%$ for subjects with uninvestigated dyspepsia and about $60 \%$ for persons with FD. However, in two of three cases, patients consulted for nongastrointestinal symptoms. These two populations of consulting and nonconsulting subjects with FD should not be seen as two distinct stable groups. Indeed, 
consulters are likely to be the same subjects who were previously living with mild and tolerable symptoms, as in phases of residual low grade symptoms alternating with phases of exacerbations. The following initial question to the patient with dyspepsia may reveal a clue to the precise diagnosis: "For how long in your life, beyond your current complaints, have you had stomach problems, even if they were previously mild and easily tolerable?". The physician should then have the patient describe the course of his or her symptoms.

Step 2: Characterize the current symptoms and review the alarm symptoms: Dyspepsia has been classified into specific symptom clusters (ulcer-type, GERD-type and dysmotilitytype) and an unspecified type. Although these subgroups have also been proposed for FD, reviews of drug therapy used for this condition report that in the vast majority of clinical trials, dysmotility-type dyspepsia is the most common subgroup, occurring much more often as a single entity than in conjunction with other complaints (26-28). In a recent Canadian study, dysmotility-type symptoms were the main dyspeptic symptoms encountered among symptomatic respondents from the general population (5). This is consistent with clinical experience that in patients with FD, including those consulting primarily for epigastric pain (classified in the ulcer-type group), dysmotility-type symptoms are very frequent and may represent the chronic-based symptoms of FD. Until now, no study has looked at the actual frequency of those symptoms in the classic subgroups of FD. However, the high frequency of overlap between subgroups is consistent with this hypothesis $(2,3,17)$. In a recent patient-based study, postprandial fullness and epigastric pain accounted for $94 \%$ and $84 \%$, respectively, of frequently reported symptoms (13). Furthermore, the first working party on dyspepsia recognized that dysmotility-type dyspepsia was the most common subgroup, while ulcer-type dyspepsia was said to occur in only a small group of patients (36). It can, therefore, be reasonably assumed that dysmotility-type dyspepsia includes pain as well as discomfort and is the most common complaint in patients with FD.

In a large cohort of patients with dyspepsia, factors leading to the clinical diagnosis of peptic ulcer were identified; history of a previous peptic ulcer (eg, a prior episode similar to the current symptoms) and pain relieved by antacid or food were good predictors of peptic ulcer in patients older than 40 years of age, with a sensitivity of $64 \%$ and a specificity of $75 \%$ (37). GERD-type dyspepsia has been discarded as a subgroup of FD (1) on the basis that patients with dyspepsia and heartburn, where heartburn is the dominant complaint, are considered to have symptomatic GERD, because a significant proportion of patients with pathological reflux have no macroscopic esophagitis (38). When heartburn or acid regurgitation clearly dominates the patient's complaints, these symptoms have a very high specificity $(89 \%$ and $95 \%$, respectively) but a low sensitivity (38\% and $6 \%$, respectively) for GERD diagnosed by $24 \mathrm{~h}$ esophageal $\mathrm{pH}$ monitoring (39).

Although only a minority of patients with dyspepsia have a peptic ulcer or complicated reflux esophagitis and even fewer have cancer (13), to minimize the risk of clinically misclassifying patients as having $\mathrm{FD}$, the presence of any alarm symptoms (unintentional weight loss, severe vomiting, dysphagia, hematemesis, melena, fever, jaundice, or other symptoms or signs suggestive of a serious or a malignant disease) must be looked for and, if present, lead to immediate appropriate investigation.

This second step of the structured interview aims to review systematically all symptoms of dyspepsia. FD includes a primary symptom, pain or discomfort in the epigastrium or upper abdomen, and secondary symptoms classically referred to as dysmotility-type symptoms (postprandial fullness, upper abdominal bloating, early satiety, nausea) $(1,28)$. In French-speaking populations, the symptom of slow or prolonged digestion after meals is also very commonly reported by patients and is meaningful to physicians $(40,41)$. This symptom is a result of the process of digestion that feels unfinished $2 \mathrm{~h}$ after a meal and is different from epigastric bloating that may occur independently or appear more than $2 \mathrm{~h}$ after a meal. With a clear definition, this dysmotilitytype symptom is more than a cultural curiosity. The dominant symptom of GERD is heartburn, defined as a burning sensation under the lower part of the centre of the chest that rises toward or into the neck and that is frequently aggravated by consumption of food or by changes in posture such as lying or stooping $(36,39,42)$. It is worth taking note that with this current definition of heartburn, relief of pain by antacid or food is not taken into account; if it were, the predictive value of this symptom would probably be enhanced, with less chance of confusion with other diagnoses such as somatoform disorder. According to this process of a symptom-based diagnosis, patients with ulcer-type symptoms should be considered to have PUD until proven otherwise and patients with predominant heartburn and/or acid regurgitation to have GERD until proven otherwise. Those with dysmotility-type dyspepsia are expected to form the major group of patients and may reasonably be considered to have $\mathrm{FD}$ as the clinical working diagnosis.

Step 3: Determine the patient's perceived dominant symptom and/or condition: The classical subgrouping of FD appears problematic for several reasons: there is considerable overlap between groups $(2,3,17)$, the symptom subgroups do not correlate with specific pathophysiological disturbances (43-45) and they do not predict specific therapeutic response $(27,28)$. This classification has, therefore, not proved to be clinically relevant in patients with FD. A different approach based on the most bothersome symptom and divided into pain-dominant and discomfort-dominant has been suggested by several clinical investigators $(13,28,41)$. Discomfort is defined as a subjective negative sensation that does not reach the level of pain (28). In practice, this classification usually refers to the presence of dysmotility-type symptoms alone and to the presence of the same symptoms along with a predominance of pain. In one study (13), $80 \%$ of patients with FD identified postprandial fullness and 54\% identified epigastric pain as relevant or severe; $46 \%$ of 343 patients qualified pain as absent or mild. Severe and relevant 
postprandial epigastric fullness and severe vomiting were predictors of delayed gastric emptying, while patients with relevant and severe epigastric pain showed accelerated emptying compared with patients with an absent or a mild degree of the symptom. A recent multicentre trial (34) also supports the clinical impact of this classification by predicting a therapeutic response; treatment with omeprazole was associated with a small but significant therapeutic gain in patients with epigastric pain as the dominant symptom, while there was no benefit in patients with discomfort as the dominant symptom. However, the presence of associated GERD may explain the response to proton pump inhibitors (PPIs) in patients with FD (46).

Patients with FD should also be asked about their most bothersome symptom(s) because reflux symptoms are common in patients with any upper gastrointestinal tract disease including FD (in about one of three) (17). In these patients, heartburn can occur because of increased esophageal acid exposure or because of increased mucosal sensitivity to physiological acid reflux (47). However, heartburn and dysmotility-type symptoms (FD) should be explained by distinct pathophysiological mechanisms in these patients. Therefore, overlapping of symptoms in patients with FD should be seen as the coexistence of conditions. The interview should establish the dominant one of the two or more conditions occurring in the patient. Irritable bowel syndrome (IBS) frequently coexists with FD $(2,3)$. Although there are similarities in pathophysiological features between the two conditions (a generalized visceral hypersensitivity [48-50]), FD can and should be distinguished from IBS on the basis of symptom criteria $(51,52)$ and therapeutic management strategies. This third step of the structured interview aims primarily to determine the most bothersome symptom (pain or discomfort) in the patient with FD. In addition, while it should be recognized that symptoms of GERD and/or IBS frequently coexist rather than overlap with the symptoms of FD, a predominant condition may be established. This approach should lead to appropriate management of the patient's expectations because there is no single or simple therapeutic management strategy that consistently resolves symptoms of different sources. Patients with predominant dysmotility-type symptoms should initially be managed as patients with pure FD.

Step 4: Identify the patient's reason for consulting and address psychosocial factors: Because a significant proportion of patients with FD do not seek medical attention, factors leading a patient to consult a physician may reveal personal characteristics that may lead to intervention strategies having a beneficial effect on the outcome. In two communitybased studies $(2,53)$, patients who had a prior history of consultation for dyspepsia (most of them having FD and/or GERD) often reported anxiety and fear of a serious condition. The severity or the frequency of symptoms was a factor leading to consultation in one but not the other study. In a patient-based study involving patients with FD and/or heartburn, anxiety and worries were the target complaints in 65\%, followed in frequency by various psychosocial problems and, third, by dyspepsia itself (54). Therefore, factors other than symptoms per se often drive a patient to consult a physician.

Although no unique personality profile characterizes patients with FD (55-57), they tend to be more anxious, neurotic, depressive and inclined to somatization than healthy subjects (56) but with a frequency similar to that in patients with other gastrointestinal organic or functional disorders (58). A well designed study documented a higher frequency of psychological features among FD patients (anxiety, general psychopathology, lower general level of functioning and multisystem complaints) than in healthy control subjects (59). This may explain the increased need for sick leave in patients with FD, a mean of 2.6 times that for a control population (60). Interestingly, this was often the result of musculoskeletal rather than abdominal symptoms. There is no formal study comparing consulters and nonconsulters in FD. Nonetheless, information extrapolated by analogy from studies of IBS $(61,62)$ suggests that psychological distress influences the decision of a subject to consult but does not explain the pathophysiological abnormalities responsible for the symptoms. Psychological and social factors are also associated with individuals with GERD who seek medical help (63).

The last step of the structured interview aims to address patients' concerns overtly and to explore psychosocial issues. Clinical experience shows that often patients do not spontaneously discuss their fears and problems when consulting with physical complaints. It is, therefore, the physician's responsibility and opportunity to use open-ended questions to meet patients' expectations. Reassuring patients about their fears of cancer or other serious diseases initiates patient management in a global approach.

\section{ASCERTAIN, WHEN APPROPRIATE, THAT THE UPPER GASTROINTESTINAL TRACT IS NORMAL}

A definite diagnosis of FD requires appropriate investigation. However, there are several reasons why investigation is recommended only in specific situations. Dyspepsia is very common in patients consulting primary care physicians (10), availability of resources is limited, health care economics have to be considered, and the three common causes of dyspepsia (the most frequent being FD) have specific and different management strategies. Patients with ulcer-type or with GERD-type dyspepsia should be considered to have that diagnosis until proven otherwise. Canadian consensus guidelines for each condition have recently been published. If uncomplicated PUD is suspected, nonendoscopic tests for $H$ pylori can be used by primary care physicians (24). If uncomplicated GERD is the clinical diagnosis, the majority of patients require no investigation and may be directed to a therapeutic trial (25). The challenge is to establish the need for and the type of long term therapy.

Despite the complexity of the therapy decision, no guidelines have been published specifically on FD. Dysmotilitytype dyspepsia can be diagnosed by careful clinical history and probably represents the vast majority of FD cases. In this 
group, the results of investigations frequently turn out to be normal. That the upper gastrointestinal tract is normal or that abnormalities do not explain the patient's dominant symptoms (such as reflux esophagitis in a patient with FD [64]) should be verified in the following situations (low threshold situations): patients with alarm symptoms or signs, patients older than 45 years of age with a new onset or a change in their symptomatology, patients with unresolved cancer fear and patients with symptoms that are perceived to be severe (ie, have a marked effect on the quality of life) by the patient or the physician. Age is a predictive factor of gastric cancer, and incidence rates show that it seems reasonable to consider age 45 years as a threshold indication for investigation (65).

If a decision is made to investigate a patient with dyspepsia, endoscopy is a safe and accurate technique, and should be the first diagnostic test performed, as recommended by the American College of Physicians guidelines (23). However, this resource is not available to the same extent in all geographic areas and consequently, primary care physicians often use upper gastrointestinal series, which are less expensive and easily accessible. However, radiography has consistently been shown to provide inferior diagnostic accuracy in detecting structural causes of dyspepsia $(66,67)$. In order to decrease the risk of wrong diagnosis with upper gastrointestinal series, a process of matching a carefully established clinical diagnosis and a radiographic report should lead the physician to pursue the investigation with endoscopy each time that there is discordance. This may be seen as a step-up approach to the investigation. Solid-phase gastric emptying tests are most often normal in patients with FD and should be reserved for high risk patients who may have gastroparesis, and those with severe postprandial epigastric bloating or severe vomiting (13).

\section{SUGGESTED APPROACH TOWARD THE CLINICAL DIAGNOSIS AND MANAGEMENT OF FD}

A well conducted structured interview should enable the physician to identify patients with presumed structural causes of dyspepsia and to be aware of nongastrointestinal causes of symptoms. Among those, somatoform disorder, a disease that manifests as abnormal concern with bodily functions and is associated with multisystem complaints, can be confused with functional dyspepsia, an organic nonstructural disease. This disorder is often encountered in a general medical setting (68). While patients with functional gastrointestinal disease have an excessive tendency to complain of bodily sensations, this characteristic is also seen in patients who have structural diseases. However, patients with a somatoform disorder report a higher frequency and a higher severity of multisystemic complaints than patients with a functional gastrointestinal condition (69). In somatoform patients, pain may be the predominant focus of clinical attention, often associated with psychological factors (68). Clinical experience indicates that these patients often have continuous pain, epigastric or retrosternal, that is not meal- related as is expected with FD or GERD, and is unaffected by relieving factors or gastrointestinal drugs. Such patients most often present with unspecified dyspepsia and would likely benefit from early investigation. The etymological definition of dyspepsia refers to bad digestion, meaning that the process of normal digestion is felt to be disturbed. Symptoms are, therefore, related to meals.

Given the clinical diagnosis of FD as previously discussed, the primary management option favours a drug trial, if needed. The whole therapeutic process involves several items that may affect this decision, such as informing the patient that the symptoms are real and that the digestive tract investigation would be normal. Simple reassurance is neither enough nor appropriate. Suggestions for lifestyle changes may also suffice. If a drug trial is needed, there is no evidence that $\mathrm{H}_{2}$ receptor antagonists are useful unless GERD symptoms predominate (26). Prokinetics may be the initial therapy in most patients with FD because dysmotility-type symptoms are their most frequent complaints and because this type of drug has been shown to be superior to placebo and to antisecretory drugs in randomized controlled trials $(28,70)$. However, it can be speculated that prokinetics are more effective in patients with predominant discomfort rather than in patients with dominant pain. Properly designed clinical trials with these drugs are needed to assess further the clinical relevance of this classification. PPIs, particularly if GERD coexists, and, in the future, drugs acting primarily on visceral perception may be alternatives for patients with predominance of pain (34). For this reason, clinicians also have used antispasmodics in patients with FD. This anecdotal experience may be understandable now that it is recognized that patients with dominant pain usually have a normal or accelerated gastric emptying (13). In selected or difficult cases, antidepressants, stress management or psychotherapy may deserve consideration.

Investigation is reserved for low threshold situations as outlined previously. It is suggested that $H$ pylori testing be recommended for patients with ulcer-type symptoms and then on a case by case basis for patients with the clinical diagnosis of $\mathrm{FD}$, only when treatment of the infection is planned (24). There is no convincing evidence to suggest that the treatment of $\mathrm{H}$ pylori alleviates symptoms in patients with FD (71). However, misdiagnosis of PUD as FD may occur, despite that these two conditions may coexist (17). Patients with coexisting ulcer-type symptoms, those insisting on being tested and patients with a close family history of PUD may be cases where investigating $H$ pylori is appropriate. As in the general population, $H$ pylori infection is common in patients with FD (72). However, in a study comparing FD patients with well-matched controls, the prevalence of $\mathrm{H}$ pylori infection was less than $50 \%$ in both groups (73). Results of $H$ pylori eradication on alleviating symptoms one year after treatment conflict. A unicentre British study (74) reported resolution of dyspepsia in $21 \%$ of patients after eradication therapy and in only $7 \%$ of placebo-treated patients. In contrast, in two multicentre international studies $(75,76)$, the rate of resolution of dyspeptic symptoms was 
similar between the placebo and active treatment groups; this rate was similar to that of the active treatment group in the previous study (74). Because most patients with FD are not infected with $\mathrm{H}$ pylori and if eradication therapy is effective it is limited to a small proportion of patients, most patients with FD would not benefit from this treatment. Until clinical predictors of response to $H$ pylori eradication, if these exist, are known, making decisions on a case by case basis is a sound approach for patients with FD. This approach may save costs by postponing testing for $\mathrm{H}$ pylori at this step of the algorithm (versus at the beginning of the process for most patients presenting with undiagnosed dyspepsia) and improve patient's satisfaction because most of the treated patients would not have PUD (24) and, hence, remain symptomatic. The majority of recommendations on the indication for investigation in patients with chronic dyspepsia, most of whom have FD, are based on consensus and expert analysis of retrospective work $(18,19,23-25,77)$ or on mathematical models linked to partially validated assumptions of limited generalization (78-80). Until well designed prospective studies are available and results are applicable to the various

\section{REFERENCES}

1. Talley NJ, Colin-Jones D, Koch KL, Koch M, Nyrén O, Stanghellini V. Functional dyspepsia: A classification with guidelines for diagnosis and management. Gastroenterol Int 1991;4:145-60.

2. Talley NJ, Zinsmeister AR, Schleck CD, Melton LJ III. Dyspepsia and dyspepsia subgroups: A population-based study. Gastroenterology 1992;102:1259-68.

3. Agréus L, Svärdsudd K, Nyrén O, Tibblin G. Irritable bowel syndrome and dyspepsia in the general population: overlap and lack of stability over time. Gastroenterology 1995;109:671-80.

4. Drossman DA, Li Z, Andruzzi E, et al. U.S. household survey of functional gastrointestinal disorders: prevalence, sociodemography, and health impact. Dig Dis Sci 1993;38:1569-80.

5. Tougas G, Hwang P, Paterson WG, et al. Dyspeptic symptoms in the general Canadian population: prevalence and impact on quality of life. Gastroenterology 1998;114:A312. (Abst)

6. Jones R, Lydeard S. Dyspepsia in the community: a follow-up study. Br J Clin Pract 1992;46:95-7.

7. Talley NJ, Weaver AI, Zinsmester AR, Melton LJ III. Onset and disappearance of gastrointestinal symptoms and functional gastrointestinal disorders. Am J Epidemiol 1992;136:165-77.

8. Holtmann G, Goebell H, Talley NJ. Dyspepsia in consulters and non-consulters: prevalence, health-care seeking behavior and risk factors. Eur J Gastroenterol Hepatol 1994;6:917-24.

9. Agréus L. Socio-economic factors, health care consumption and rating of abdominal symptom severity: a report from the abdominal symptom study. Fam Pract 1993;10:152-63.

10. Knill-Jones RP. Geographical differences in the prevalence of dyspepsia. Scand J Gastroenterol Suppl 1991;182:17-24.

11. Williams B, Luckas M, Ellingham JH, Dain A, Wicks AC. Do young patients with dyspepsia need investigation? Lancet 1988;ii:1349-51.

12. Heikkinen P, Pikkarainen P, Takala J, Julkunen R. General practitioners' approach to dyspepsia. Scand J Gastroenterol 1996;31:648-53.

13. Stanghellini V, Tosetti C, Paternicò A, et al. Risk indicators of delayed gastric emptying of solids in patients with functional dyspepsia. Gastroenterology 1996;110:1036-42.

14. Nyrén O, Adami HO, Gustavsson S, Loof L, Nyberg A. Social and economic effects of non-ulcer dyspepsia. Scand J Gastroenterol 1985;109:41-7

15. Nyrén O, Lindberg G, Lindstrom E, Marke LA, Seensalu R. Economic costs of functional dyspepsia. Pharmacoeconomics 1992;1:312-4.

16. Dyspepsia Management Guidelines. London: British Society of Gastroenterology, September 1996.

17. Talley NJ, Weaver AL, Tesmer DL, Zinsmeister AR. Lack of discriminant value of dyspepsia subgroups in patients referred for upper endoscopy. Gastroenterology 1993;105:1378-86. regions of practice, management strategies in patients with dyspepsia or with FD remain unresolved. Results of a recent randomized controlled trial of $\mathrm{H}$ pylori testing or prompt endoscopy in 475 primary care patients with dyspepsia suggest an improved short term outcome with endoscopy (81). Rather than diagnosing FD by excluding other conditions, establishing a clinically based diagnosis initially may be a positive approach and may have some of the benefits reported after a normal endoscopy, such as fewer office visits and sick days, fewer consultations for gastrointestinal symptoms, reduced rate of prescribing, lower drug costs and improved satisfaction with care $(29,82,83)$.

ACKNOWLEDGEMENTS: The author thanks members of the Non Ulcer Dyspepsia Working Group (Drs Richard Fedorak, Robert J Bailey, Daniel Sadowski, Naoki Chiba, Stephen Collins, Michel Boivin, Dilip Patel, William Paterson, C Noël Williams, Malcolm Champion and Brian Morris), Mrs Rachel Simard for her expert secretarial assistance and Mrs Lynne Moore MSc (epidemiology) for her critical advice.

18. Current European Concepts in the management of Helicobacter pylori infection. The Maastricht Consensus Report. Gut 1997;41:8-13.

19. American Gastroenterological Association Medical Position Statement: Evaluation of Dyspepsia. Gastroenterology 1998;114:579-81.

20. Chiba N, Bernard L, O'Brien BJ, Goeree R, Hunt RH. A Canadian physician survey of dyspepsia management. Can J Gastroenterol 1998;12:83-90.

21. Talley NJ, Phillips SF, Melton LJ III, Wiltgen C, Zinsmeister AR. A patient questionnaire to identify bowel disease. Ann Intern Med 1989;111:671-4.

22. Talley NJ, Phillips SF, Wiltgen CM, Zinsmeister AR, Melton LJ III. Assessment of functional gastrointestinal disease: the Bowel Disease Questionnaire. Mayo Clin Proc 1990;65:1456-79.

23. Health and Public Policy Committee. Endoscopy in the evaluation of dyspepsia. Ann Intern Med 1985;102:266-9.

24. Hunt R, Thomson ABR, Consensus Conference participants. Canadian Helicobacter pylori Consensus Conference. Can J Gastroenterol 1998;12:31-41.

25. Beck IT, Champion MC, Lemire S, et al. The Second Canadian Consensus Conference on the Management of Patients with Gastroesophageal Reflux Disease. Can J Gastroenterol 1997;11(Suppl B): 7B-20B.

26. Dobrilla G, Comberlato M, Steele A, Vallaperta P. Drug treatment of functional dyspepsia. A meta-analysis of randomized controlled clinical trials. J Clin Gastroenterol 1989;11:169-77.

27. Talley NJ. Drug treatment of functional dyspepsia. Scand J Gastroenterol 1991;26(Suppl 182):47-60.

28. Veldhuyzen van Zanten SJO, Cleary C, Talley NJ, et al. Drug treatment of functional dyspepsia: a systematic analysis of trial methodology with recommendations for design of future trials. Am J Gastroenterol 1996;91:660-73.

29. The Report of the Digestive Health Initiative ${ }^{\mathrm{sm}}$ International Update Conference on Helicobacter pylori. Gastroenterology 1997;113:54-8.

30. Bytzer P, Hansen JM, Schaffalitzky de Muckadell OB. Empirical $\mathrm{H}_{2}$-blocker therapy or prompt endoscopy in management of dyspepsia. Lancet 1994;343:811-6.

31. Soll AH. Peptic ulcer and its complications. In: Feldman M, Scharschmidt BF, Sleisenger MH, eds. Gastrointestinal and Liver Disease, 6th edn. Philadelphia: Saunders, 1998:620-65.

32. Kitchin LI, Castell DO. Rationale and efficacy of conservative therapy for gastroesophageal reflux disease. Arch Intern Med 1991;151:448-54

33. Locke GR III, Talley NJ, Felt SL, et al. Prevalence and clinical spectrum of gastroesophageal reflux: a population-based study in Olmstead County, Minnesota. Gastroenterology 1997;112:1448-56. 
34. Talley NJ, Meineche-Schmidt V, Paré P, et al. Efficacy of omeprazole in functional dyspepsia: double-blind randomized placebo-controlled trials. (the Bond and Opera studies). Aliment Pharmacol Ther 1998;12:1055-65.

35. Jones R, Lydeard S. Prevalence of symptoms of dyspepsia in the community. Br Med J 1989;298:30-2.

36. Colin-Jones DG, Bloom B, Bodemar G, et al. Management of dyspepsia: Report of a working party. Lancet 1988;i:576-9.

37. Johannessen T, Petersen H, Kleveland PM, et al. The predictive value of history in dyspepsia. Scand J Gastroenterol 1990;25:689-97.

38. Johnsson F, Joelsson B, Gudmundsson K, Greiff L. Symptoms and endoscopic findings in the diagnosis of gastroesophageal reflux disease. Scand J Gastroenterol 1987;22:714-8.

39. Klauser AG, Schindlbeck NE, Müller-Lissner SA. Symptoms in gastro-oesophageal reflux disease. Lancet 1990;335:205-8.

40. Jian R, Ducrot F, Ruskone A, et al. Symptomatic, radionuclide and therapeutic assessment of chronic idiopathic dyspepsia. Dig Dis Sci 1989;34:657-64.

41. Paré $\mathrm{P}$, Bradette $\mathrm{M}$. Reconnaître et soulager les problèmes digestifs fonctionnels. Le Clinicien 1996;11:147-59.

42. Richter JE, Baldi F, Clouse RE, Diamant NE, Janssens J, Staiano A. Functional esophageal disorders. Gastroenterol Int 1992;5:3-17.

43. Waldron B, Cullen PT, Kumar R, et al. Evidence for hypomotility in non-ulcer dyspepsia: a prospective multifactorial study. Gut 1991;32:246-51.

44. Talley NJ, Shuter B, McCrudden G, Jones M, Hoschi R, Piper DW. Lack of association between gastric emptying of solids and symptoms in nonulcer dyspepsia. J Clin Gastroenterol 1989;11:625-30.

45. Greydanus MD, Vassallo M, Camilleri M, Nelson DK, Hanson RB, Thomforde GM. Neurohormonal factors in functional dyspepsia: insights on pathophysiological mechanisms. Gastroenterology 1991;100:1311-8.

46. Farup PG, Hovde $\phi$, Torp R, Wetterhus S. Patients with functional dyspepsia responding to omeprazole have a characteristic reflux pattern. Gastroenterology 1998;114:A1000. (Abst)

47. Small PK, Loudon MA, Waldron B, Smith D, Campbell FC. Importance of reflux symptoms in functional dyspepsia. Gut 1995;36:189-92.

48. Trimble KC, Farouk R, Pryde A, Douglas S, Heading RC. Heightened visceral sensation in functional gastrointestinal disease is not site-specific: evidence for a generalized disorder of gut sensitivity. Dig Dis Sci 1995;40:1607-13.

49. Zighelboim J, Talley NJ, Phillips SF, Harmsen WS, Zinmeister AR. Visceral perception in irritable bowel syndrome: rectal and gastric responses to distension and serotonin type 3 antagonism. Dig Dis Sci 1995;40:819-27.

50. Holtmann G, Goebell H, Talley NJ. Functional dyspepsia and irritable bowel syndrome: Is there a common pathophysiological basis? Am J Gastroenterol 1997;92:954-9.

51. Manning AP, Thompson WG, Heaton KW, Morris AF. Towards positive diagnosis of the irritable bowel. Br Med J 1978;2:653-4.

52. Talley NJ, Phillips SF, Melton LJ, Mulvihill C, Wiltgen C, Zinsmeister AR. Diagnostic value of the Manning criteria in irritable bowel syndrome. Gut 1990;31:77-81.

53. Lydeard S, Jones R. Factors affecting the decision to consult with dyspepsia: comparison of consulters and non-consulters. J R Coll Gen Pract 1989;39:495-8.

54. Haug TT, Wilhelmsen I, Ursin H, Berstad A. What are the real problems for patients with functional dyspepsia? Scand J Gastroenterol 1995;30:97-100.

55. Talley NJ, Jones M, Piper DW. Psychosocial and childhood factors in essential dyspepsia. Scand J Gastroenterol 1988;23:341-6.

56. Richter JE. Stress psychologic and environmental factors in functional dyspepsia. Scand J Gastroenterol 1991;26(Suppl 182):40-6.

57. Drossman DA. Psychosocial factors in functional dyspepsia. Eur J Gastroenterol Hepatol 1992;4:602-7.

58. Talley NJ, Phillips SF, Bruce B, Twomey CK, Zinsmeister AR, Melton LJ III. Relation among personality and symptoms in nonulcer dyspepsia and the irritable bowel syndrome. Gastroenterology 1990;199:327-33.

59. Haug TT, Svebak S, Wilhelmsen I, Berstad A, Ursin H. Psychological factors and somatic symptoms in functional dyspepsia: a comparison with duodenal ulcer and healtly controls. J Psychosom Res 1994;38:281-91.
60. Nyrén O, Adami H, Gustavsson S, Loof L. Excess sick-listing in nonulcer dyspepsia. J Clin Gastroenterol 1986;8:339-45.

61. Drossman DA, McKee Dc, Sandler RS, et al. Psychosocial factors in the irritable bowel syndrome: A multivariate study of patients and nonpatients with irritable bowel syndrome. Gastroenterology 1988;95:701-8.

62. Whitehead WE, Bosmajian L, Zonderman AB, Costa PT Jr, Schuster MM. Symptoms of psychological distress associated with irritable bowel syndrome: comparison of cummunity and medical clinic samples. Gastroenterology 1988;95:709-14.

63. Johnston BT, Gunning J, Lewis SA. Health care seeking by heartburn sufferers is associated with psychosocial factors. Am J Gastroenterol 1996;91:2500-4.

64. Boyd EJS. The prevalence of esophagitis in patients with duodenal ulcer or ulcer-like dyspepsia. Am J Gastroenterol 1996;91:1539-43.

65. Axon ATR. Chronic dyspepsia: who needs endoscopy? Gastroenterology 1997;112:1376-80.

66. Shaw PC, van Romunde LK, Griffioen G, Janssens AR, Kreuning J, Eilers GA. Peptic ulcer and gastric carcinoma: diagnosis with biphasic radiography compared with fiberoptic endoscopy. Radiology 1987;167:39-42.

67. Dooley CP, Larson AW, Stace NH, et al. Double-contrast barium meal and upper gastrointestinal endoscopy: a comparative study. Ann Intern Med 1984;101:538-45.

68. American Psychiatric Association: Diagnostic and Statistical Manual of Mental Disorders, 4th edn. Washington: American Psychiatric Association, 1994:445-69.

69. Talley NJ, Phillips SF, Bruce B, Zinsmeister AR, Wiltgen C, Melton LJ. Multisystem complaints in patients with the irritable bowel syndrome and functional dyspepsia. Eur J Gastroenterol Hepatol 1991;3:71-7.

70. Finney JS, Kinnersley N, Hugues M, O'Bryan-Tear CG, Lothian J. Meta-analysis of antisecretory and gastrokinetic compounds in functional dyspepsia. J Clin Gastroenterol 1998;26:312-20

71. Talley NJ, Hunt RH. What role does Helicobacter pylori play in dyspepsia and nonulcer dyspepsia? Arguments for and against $H$ pylori being associated with dyspeptic symptoms. Gastroenterology 1997;113:S67-77.

72. Armstrong D. Helicobacter pylori infection and dyspepsia. Scand J Gastroenterol 1996;31(Suppl 215):38-47.

73. Bernersen B, Johnsen R, Bostad L, Straume B, Sommer A-I, Burhol PG. Is Helicobacter pylori the cause of dyspepsia? BMJ 1992;304:1276-9.

74. McColl K, Murray L, El-Omar E, et al. Symptomatic benefit from eradicating Helicobacter pylori infection in patients with nonulcer dyspepsia. N Engl J Med 1998;339:1869-74.

75. Talley NJ, Janssens J, Lauritsen K, et al. Long-term follow-up of patients with non-ulcer dyspepsia after Helicobacter pylori eradication. A randomized double-blind placebo-controlled trial. Gastroenterology 1998;114:A305. (Abst)

76. Blum AL, Talley NJ, O'Morain CA, et al. Lack of effect of treating Helicobacter pylori infection in patients with nonulcer dyspepsia. N Engl J Med 1998;339:1875-81.

77. AGA Technical Review: Evaluation of Dyspepsia. Gastroenterology 1998;114:582-95.

78. Fendrick AM, Chernew ME, Hirth R, Bloom BS. Alternative management strategies for patients with suspected peptic ulcer disease. Ann Intern Med 1995;123:260-8.

79. Silverstein MD, Petterson T, Talley NJ. Initial endoscopy or empirical therapy with or without testing for Helicobacter pylori for dyspepsia: a decision analysis. Gastroenterology 1996;110:72-83.

80. Ofman JJ, Etchason J, Fullerton S, Kahn KL, Soll AH. Management strategies for Helicobacter pylori - seropositive patients with dyspepsia: clinical and economic consequences. Ann Intern Med 1997;126:281-91.

81. Lassen AT, Bytzer P, Schaffalitzky de Muckadell OB. H. Pylori testing or prompt endoscopy for dyspeptic patients in primary care. A randomized controlled trial of two management strategies. Gastroenterology 1997;112:A24. (Abst)

82. Jones R. What happens to patients with non-ulcer dyspepsia after endoscopy? Practitioner 1988;232:75-8.

83. Hugin APS, Thomas PR, Bramble MG, et al. What happens to patients following open access gastroscopy? An outcome study from general practice. Br J Gen Pract 1994;44:519-21. 


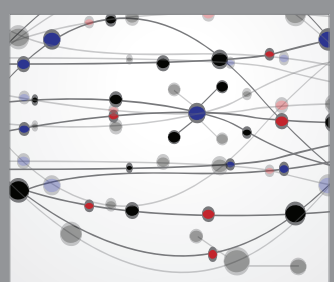

The Scientific World Journal
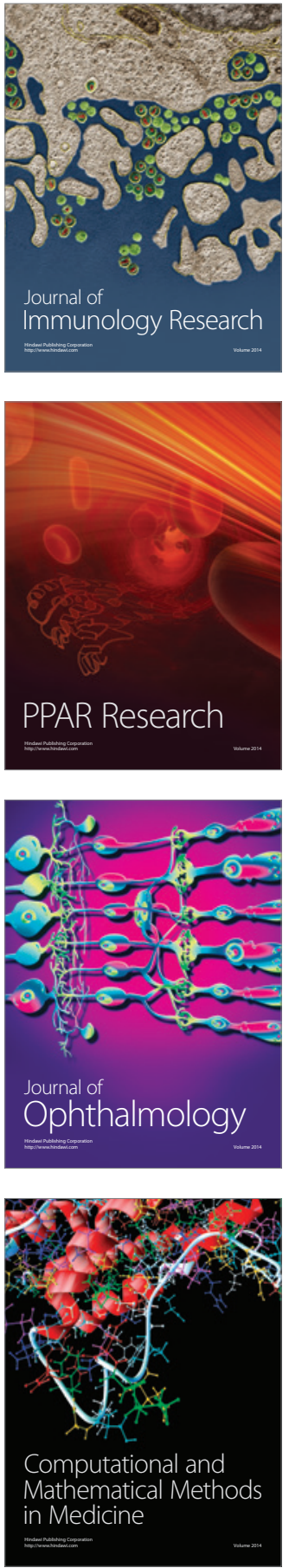

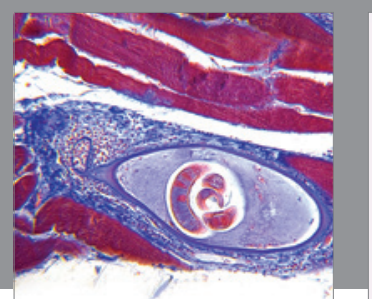

Gastroenterology Research and Practice

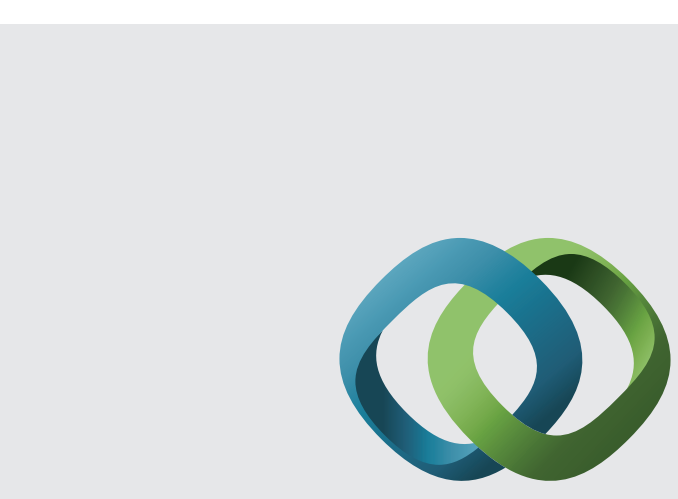

\section{Hindawi}

Submit your manuscripts at

http://www.hindawi.com
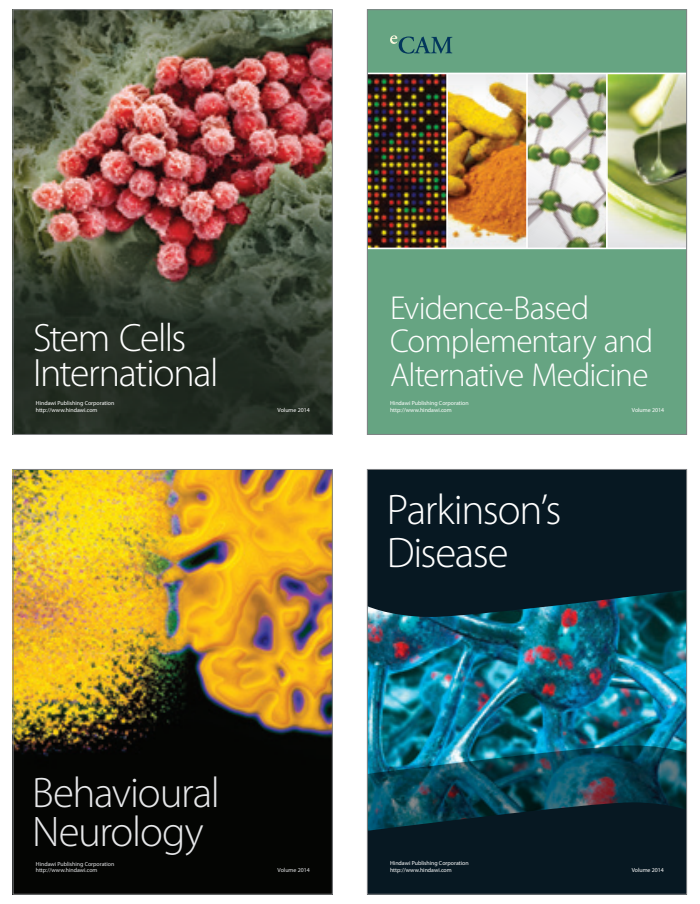
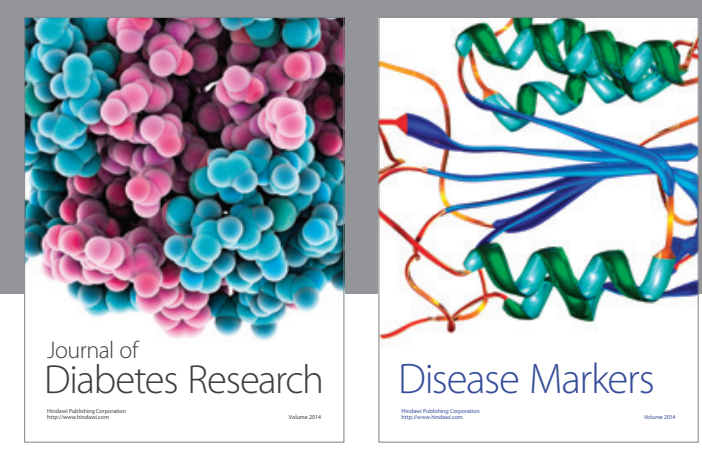

Disease Markers
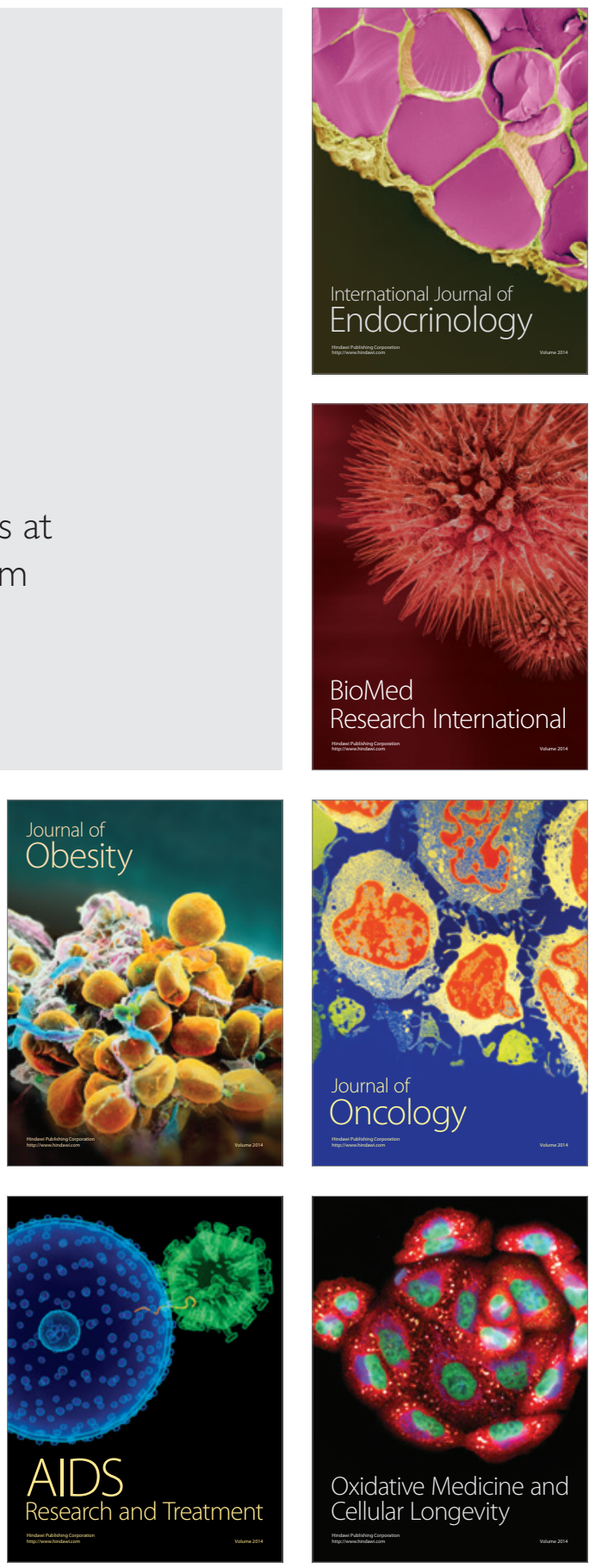